\title{
Primary Disseminated Intra-abdominal Hydatid Disease: A Case Report
}

\author{
Zaman $\mathrm{S}^{\mathrm{a}}$, Rahim $\mathrm{MA}^{\mathrm{b}}$, Uddin $\mathrm{KN}^{\mathrm{c}}$
}

\begin{abstract}
Hydatid disease in human is common and liver is the most common site of involvement followed by lungs. Within the abdomen, hydatid disease can disseminate to involve spleen, pancreas, mesentery, kidney, ovary, gut, supra-renal glands etc. Such disseminations are usually secondary to rupture of a cyst: spontaneous, iatrogenic or traumatic. Without such a history, primary disseminated intra-abdominal hydatidosis is rare. Here we present such a case.
\end{abstract}

Key words: Echynococcosis, Echynococcus granulosus, hydatid disease, primary.

(BIRDEM Med J 2018; 8(1): 75-76)

\section{Introduction}

Echynoccosis or hydatid disease, caused by Echynococcus granulosus, is common and three-fourth of hydatid disease in human involves the liver, but no organ is immune. ${ }^{1}$ Usually intra-abdominal dissemination occurs secondary to rupture of a hepatic cyst. Primary intra-abdominal dissemination is rare. Presentation depends upon organ involvement. ${ }^{2,3}$ Eiosinophilia is common. Typical radiological features along with positive serology are sufficient to make a diagnosis. Direct microscopic examination of operated or aspirated cyst material is also of use. Anti-helminthic agents and surgery remains the mainstay of treatment.

\section{Case Report}

A 43-year-old lady from Tangail presented with 5-month history of progressive upper abdominal discomfort and occasional non-radiating, dull-aching pain. She did not have fever, anorexia, vomiting or weight loss. She denied any abdominal trauma. She was diabetic and on gliclazide $80 \mathrm{mg}$ daily with poor glycaemic control. She used to keep pets including dogs and sheep.

\section{Author Information \\ a. Shahana Zaman, Junior Consultant, Department of Cardiology, NICVD, Dhaka, Bangladesh. \\ b. Muhammad Abdur Rahim, Assistant Professor, Department of Nephrology, BIRDEM General Hospital, Dhaka, Bangladesh. \\ c. Khwaja Nazim Uddin, Professor, Department of Internal Medicine, BIRDEM General Hospital, Dhaka, Bangladesh.}

Address of correspondence: Muhammad Abdur Rahim, Assistant Professor, Department of Nephrology, BIRDEM General Hospital, Dhaka, Bangladesh. Email: muradrahim23@yahoo.com

Received: January 11, 2017

Accepted: October 31, 2017
The lady was thin. There was no anaemia, jaundice or lymphadenopathy. Her vital parameters were normal. She had 6-cm non-tender, smooth-surfaced hepatomegaly. There was no other intra-abdominal organomegaly, mass or ascites. Other examination findings were unremarkable.

Haematological parameters revealed eiosinophilia (8\%). Abdominal ultrasonography revealed multiple cystic lesions of variable size in liver, spleen, right adrenal gland and left ovary (Figure 1). Computed tomographic (CT) scan showed multiple cystic lesions with septation in liver, spleen, pancreas and mesentery suggesting hydatid disease (Figure 2). Echynococcus serology done by haemaglutination assay (HA method) was positive at 1:2560 dilution. Hepatic and renal biochemistry including serum electrolytes were within normal range. $\mathrm{HbAlc}$ was $8.9 \%$ and fasting blood glucose $7.8 \mathrm{~m} . \mathrm{mol} / \mathrm{L}$.

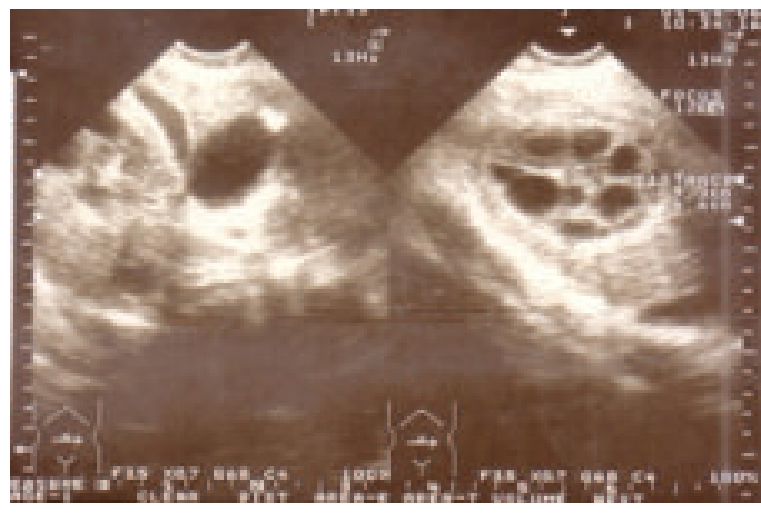

Figure 1. Ultrasonogram showing hepatic cyst with septation 


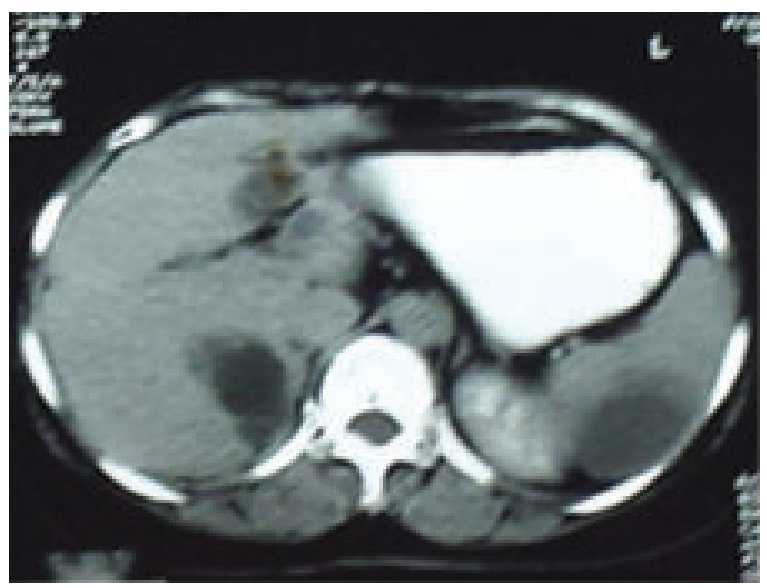

Figure 2. Computed tomography (CT) scan of abdomen showing cysts in liver and spleen

She was diagnosed as having primary disseminated intra-abdominal hydatid disease. She was prescribed albendazole $400 \mathrm{mg}$ twice daily and advised for followup after one month. She was lost and came after 13 months. Over this period she took albendazole on and off. Repeat abdominal CT scan revealed cystic lesions in liver, pancreas, spleen, mesentery and left adnexa but many of the cysts hd regressed in size. Because of extensive visceral involvement, surgery was deferred and she was put on anti-helminthics.

\section{Discussion}

Hydatid disease remains a public health problem through-out the world specially in Australia, NewZealand, Turkey, China, Brazil and Indian sub-continent, where cattle grazing are common. Dog is the definitive host and sheep is intermediate host. Man becomes accidental intermediate host when ingest contaminated food or drinks.

After ingestion, the infective agent passes the intestinal mucosa and gets lodged in liver through portal vein. ${ }^{4}$ Three-fourth of human cases involve the liver, followed by lungs. Multi-visceral involvement occurs in 13\% cases. Such disseminations are usually secondary to rupture of a primary cyst, but lymphatic or haematogenous spread are possible. ${ }^{4}$

Presentation is usually insidious, due to mass effect of an expanding cyst. Pain may occur especially if secondary bacterial infection or rupture of a cyst occurs. Fever and weight-loss are also common. Mild eiosinophilia may occur. Ultrasonography is the firstline imaging and contrast enhanced CT scan gives better detail of cyst(s). ${ }^{1}$ Immunological tests include enzyme linked immunosorbant assay (ELISA), indirect haemaglutination assay (IHA), immunochromatographic test (ICT) etc with almost similar sensitivity and specificity.

Surgery is the mainstay of treatment in conjunction to anti-helminthic agents. ${ }^{5}$ Prior administration of albendazole reduces chance of anaphylaxis and peroperative spillage and dissemination. Still dissemination and recurrence may occur in up to $10 \%$ cases. ${ }^{6}$ Postoperative albendazole and praziquantel are usually given for a variable period. Percutaneous aspiration, injection and respiration (PAIR) is established treatment option and may avoid surgery is selected cases. CT scan may help in follow-up of cases.

Many cases of hydatid disease may remain undiagnosed for years. Complications include secondary infection, rupture or dissemination. In such cases aggressive treatment is necessary otherwise outcome is unrewarding.

Conflict of interest: Nothing to declare.

\section{References}

1. Polat P, Kantarci M, Alper F, Suma S, Koruyucu MB, Okur A. Hydatid disease from head to toe. Radiographics 2003;23:475-94.

2. Goel MM, Verma N, Sagar M. Disseminated intra-abdominal hydatidosis causing acute intestinal obstruction-a rare presentation. BMJ Case Rep 2010; 2010:bcr0620103066.

3. Alimohamadi S, Dehghan A, Neghab N. Primary bilateral intrapelvic hydatid cyst presenting with adnexal cystic mass: a case report. Acta Med Iran 2011;49:694-96.

4. Kushwaha JK, Sonkar AA, Verma AK, Pandey SK. Primary disseminated extrahepatic abdominal hydatid cyst: a rare disease. BMJ Case Rep 2012;2012. pii: bcr0220125808.

5. Majbar MA, Souadka A, Sabbah F, Raiss M, Hrora A, Ahallat M. Peritoneal echinococcosis: anatomoclinical features and surgical treatment. World J Surg 2012; 36:1030-35.

6. Babu KS, Goel D, Prayaga A, Rao IS, Kumar A. Intraabdominal hydatid cyst: a case report. Acta Cytol 2008;52:464-66. 